\title{
El amparo estructural de los derechos, de Andrés Mauricio Gutiérrez Beltrán. Madrid: Centro de Estudios Políticos y Constitucionales, 2018 ${ }^{* *}$
}

\begin{abstract}
¿Deben los máximos tribunales estatales enfrentar las causas de las violaciones generalizadas de los derechos fundamentales? ¿Cómo caracterizar este tipo de decisiones? ¿Cómo legitimarlas? ¿Qué determina que algunos tribunales estatales lo hagan y otros no? Y, después de los años, ¿cuál es el balance?

El amparo estructural de los derechos es una colección bien ordenada de las respuestas a estas preguntas. Pero es más que eso. Es una buena muestra de aquellos extraños casos en los cuales el todo es superior a la suma de sus partes. Es, a la vez, una propuesta de conceptualización teórica del fenómeno de los fallos estructurales, una presentación magistral de los distintos argumentos de sus detractores y de sus valedores, una remodelación del viejo debate sobre la objeción contramayoritaria, un paseo por varios de los problemas clásicos de la teoría del derecho, y la concreción de un trabajo casi imposible de derecho comparado. Todo esto, además, logrado con la genialidad de una pluma privilegiada, que mantiene al lector en vilo a lo largo de sus casi 400 páginas. Quizá algunas de estas razones estén también detrás del premio "Nicolás Pérez Serrano" a la "mejor tesis doctoral en Derecho Constitucional" escrita en España en 2016, premio con el que fue distinguido su autor por el Centro de Estudios Políticos y Constitucionales, siendo el primer latinoamericano en merecer esta dignidad.
\end{abstract}

\section{UNA PROPUESTA ORIGINAL DE CONCEPTUALIZACIÓN}

En un ejercicio que parece meramente descriptivo, a lo largo del texto, Gutiérrez se arriesga a proponer varios elementos para una conceptualización teórica de su objeto de estudio. Es notable su original ejercicio de caracterización del fenómeno a partir de una ontología propia, al proponer las cuatro características principales de los llamados "fallos estructurales": masividad,

\footnotetext{
Docente-investigador de la Universidad Externado de Colombia (Bogotá, Colombia). Abogado de la misma Universidad y doctor en Derecho por la Universidad Autónoma de México. Contacto: juan.upegui@uexternado.edu.co orCID: 0000-0002-4649-8217.

Recibido el 1..$^{\circ}$ de junio de 2020, aprobado el 12 de junio de 2020.

Para citar la reseña: UPEgui Mejía, J. C. "El amparo estructural de los derechos", de Andrés Mauricio Gutiérrez Beltrán. Madrid: Centro de Estudios Políticos y Constitucionales, 2018. En Revista Derecho del Estado, Universidad Externado de Colombia, N. ${ }^{\circ} 47$, septiembre-diciembre de 2020, 371-377.

DOI: https://doi.org/10.18601/01229893.n47.12
} 
bloqueo institucional, órdenes complejas y supervisión; pero no una ontología estática sino una móvil, que dialoga con los problemas de escala y de gradualidad, y que se modula en una tipología de decisiones (declarativas, dialógicas, unidireccionales) que, además, abren vetas para enfrentar los problemas de legitimidad, posibilidad y eficacia de estas decisiones judiciales.

Por esta misma cuerda, es igualmente notable la elección de las categorías para desentrañar la complejidad de las causas del fenómeno, al oponer a la explicación tradicional (que finca sus razones en la extensión y el carácter del texto constitucional, más la actitud proclive al activismo de los jueces del máximo tribunal) una explicación compleja, en donde se incluyen las "estructuras de sostén". Esto es, las redes de apoyo a la causa del amparo estructural, las particularidades de la cultura jurídica subyacente y una serie no menos importante de aspectos relacionados con elementos sociológicos, el florecimiento de los litigios estratégicos y la psicología judicial.

Y por último, su muy particular lectura sobre la insuficiencia de las dos posiciones tradicionales existentes para caracterizar los efectos de estos fallos: por un lado, la posición neorrealista (concentrada en los resultados nominales), por el otro, la posición constructivista (que amplía el alcance de miras e incluye los resultados simbólicos). Gutiérrez advierte la insuficiencia de estas lecturas, no porque sean muy parca la una y muy romántica la otra, sino porque desatienden un dato básico: la centralidad de las víctimas. Y quizá aquí pueda encontrarse la clave, la inspiración profunda del ejercicio académico del autor: una genuina preocupación por la eficacia de los derechos.

\section{UNA PRESENTACIÓN EQUILIBRADA DE LAS POSICIONES ANTAGÓNICAS}

Una genuina preocupación por la eficacia de los derechos, esa es la posición de Gutiérrez. Y este es un dato del todo relevante. Porque no es fácil ubicar al autor en el contexto de las álgidas discusiones en torno al amparo estructural de los derechos. No lo es, porque no se alinea, ni toma partido. Esta tesis no es una defensa de la práctica del amparo estructural de los derechos, no es un panegírico del activismo judicial, ni se suma a las voces que pontifican sobre esta nueva forma de la "revolución de los derechos". Y, a la vez, tampoco es una tesis que se apunte en las listas de sus detractores, no es una crítica demoledora sobre sus causas y sus fundamentos, no es una defensora de la ortodoxia, ni del statu quo, ni una búsqueda pertinaz por desahuciar el activismo judicial. Frente a esta clara dificultad, las preguntas sobre cuál es en últimas la tesis defendida, y cuál la postura de su autor, cobran plena relevancia. Si no es acertado contarlo como uno de los valedores del amparo estructural, ni tampoco como uno de sus detractores, ¿entonces cómo?

El tejido argumental de la tesis es una buena muestra de un trabajo guiado por el principio de la honradez intelectual y por la fidelidad a una idea básica: la exploración de un objeto de conocimiento plagado de ideologías y de 
puntos en disputa, sin que el autor revele su compromiso con alguna de las posiciones, ni se deje seducir por el argumento fácil, o por el que parezca a primera, segunda o tercera vista el más convincente.

Metodológicamente, Gutiérrez logra tejer la urdimbre de su tesis a partir de un método que parece sencillo: a un argumento plantarle otro en contra, y a su vez a este oponerle uno que parezca mejor que el anterior, y de nuevo, a este, contraponerle otro que sea aún más difícil de derrotar. El resultado final es la saturación; un óptimo, una suerte de summum de la argumentación, en donde es muy difícil discernir cuál de las posiciones enfrentadas ha salido vencedora, o por cuál de las posiciones enfrentadas habría que apostar.

La tesis del autor está en el fondo, mientras se discute la idoneidad del complejo instrumental de las formas democráticas de gobierno actuales. Mientras se discurre por los límites, los peligros, las ventajas, las tensiones, las oportunidades de los fallos estructurales, en el fondo está, latente, de forma constante y clara, la preocupación por la eficacia de los derechos fundamentales todos, por la "realización efectiva de los derechos".

\section{UNA REMODELACIÓN DEL VIEJO DEBATE EN TORNO}

A LA OBJECIÓN CONTRAMAYORITARIA

Esta tesis es también un ejercicio de inquisición constante por el rol (debido, más adecuado, menos problemático) del máximo tribunal en el funcionamiento de un régimen democrático de gobierno. El amparo estructural de los derechos es una profunda indagación sobre lo que Chantal Mouffe ha llamado la "paradoja democrática", pero con el foco puesto ahora en los fallos estructurales como el más controvertido de los objetos. Objeto que aporta novedosos estímulos para avivar la irresoluble tensión que existe en la forma de gobierno republicana alimentada, al mismo tiempo, por la tradición democrática, la autonomía de los individuos, la representación y la regla de las mayorías por un lado, y la tradición liberal, la supremacía de la Constitución, la limitación del poder y los derechos fundamentales, por el otro.

No se trata ciertamente de una tesis más, alineada en alguno de los bandos del debate, sobre la objeción contramayoritaria. Sin querer terciar en este debate, considerado por Gutiérrez como irresoluble, el autor termina por revitalizarlo, a partir de alterar la formulación de las preguntas clave: ¿no son los derechos sociales fundamentales parte de "la órbita de lo no decidible"? ¿Es posible el renacer de la política a partir del cuestionamiento del propio contenido de los derechos fundamentales? ¿No deberían los reformistas dejar de consolarse con los efectos simbólicos de las decisiones judiciales? ¿En casos de bloqueo o de indiferencia institucional no puede (no debe) ser el máximo tribunal la chispa que avive los debates democráticos? ¿No son los fallos estructurales el síntoma de un malestar democrático y a la vez parte 
de la terapia de choque requerida? ¿No esconde la oposición aristrocraciademocracia una lectura simplista de la complejidad del fenómeno?

UN PASEO POR PROBLEMAS CLÁSICOS DE LA TEORÍA DEL DERECHO

Esta batería de nuevas preguntas sobre un problema viejo viene acompañada por una estimulante revisión de varios problemas clásicos de la teoría del derecho. Este es el otro elemento que compone el tejido general de la tesis, que la hace tan bien cuidada y tan bien lograda. Hay a lo largo del texto, entre muchas otras cosas, buenos argumentos sobre teoría de la democracia, en donde la democracia madisoniana dialoga con las formas más sofisticadas de la democracia deliberativa. Así como buenos argumentos de teoría de la Constitución, con una interrogación permanente sobre las finalidades del Estado, sobre la caracterización de las políticas públicas y el rol de distintos actores en su conformación, diseño e implementación, alternadas con reflexiones sobre las formas más adecuadas de articulación y limitación del poder público.

Hay también un muy importante componente de teoría de la decisión judicial, desde sus fundamentos hasta la concepción de los remedios, intercalados con elementos de psicología judicial y de realismo jurídico, salpicados con los siempre desafiantes argumentos de los Critical Legal Studies. Hay asimismo unos párrafos excelsos sobre las relaciones entre lenguaje y derecho, que parecen sacados de las mejores páginas de un tratado sobre teoría de la interpretación. Y tampoco se le escapan al autor elementos de la teoría general de los derechos fundamentales, en especial la caracterización de los derechos sociales como materia prima de los fallos estructurales, las obligaciones positivas de satisfacción y garantía y, por su puesto, un cuestionamiento permanente acerca del rol y la centralidad de las víctimas.

\section{UN TRABAJO CASI IMPOSIBLE DE DERECHO COMPARADO}

Es, además, un ejercicio muy audaz de derecho comparado, en donde las particularidades de los tres casos principales de estudio, los Estados Unidos de América, Sudáfrica y Colombia, se ven enriquecidas con alusiones al caso indio, se contrastan con la reticencia europea, y se acompañan con un excurso por la práctica de los tribunales internacionales de derechos humanos, la Corte Interamericana y la Corte Europea. Desde fuera no se ve cómo, en términos metodológicos, sea posible integrar componentes tan disímiles. La lectura del texto deja al lector perplejo, no por su complejidad, sino precisamente por la facilidad con la que el autor va hilando el argumento y exponiendo con lujo de detalles, no solo las particularidades de esta o aquella Constitución nacional, de esta o aquella coyuntura política decisiva, de este o aquel con- 
junto de datos pertinente, y de esta o aquella decisión judicial, explicando, a la vez que su contenido, sus detalles y sus implicaciones.

Gutiérrez, no hace una mera comparación de textos o de prácticas, ofrece al lector los elementos suficientes para sumergirse con un relativo nivel de profundidad en los pormenores de los ordenamientos jurídicos estudiados, en el contexto político de las decisiones y en las respectivas culturas jurídicas en que fueron moldeadas. Al final, el autor ha provisto al lector con las herramientas suficientes para una comprensión profunda del objeto de investigación, en donde el resultado descriptivo final, así como las categorías clasificatorias y de análisis, están enaltecidos por una capacidad de síntesis y una riqueza expositiva que le da brillo a la evidencia recogida y a la sistematización propuesta.

\section{LO QUE PUDO SER MEJOR}

En esta línea de aciertos es difícil acomodar uno que otro punto débil. Toda obra humana es perfectible y todo esfuerzo del intelecto mejorable. Pondría sobre la mesa bien servida de los argumentos antes citados tres escenarios de mejora.

El primero guarda relación con la caracterización del fenómeno. El concepto "fallo estructural" es difícil de asir. La fabulosa diversidad de las especies de la que da cuenta la tesis hace difícil que los rasgos definitorios propuestos en la ontología conceptual se presenten en todos los casos. Puede haber fallos estructurales, y hay algunos citados como tales, en los que no hay un número abultado de víctimas de uno o varios derechos fundamentales. Por ejemplo, los casos de problemas en un centro de salud para discapacitados, o de una persona de talla baja que no alcanza la ventanilla de atención en una corte, no lo satisfacen, pero sin embargo son presentados como tales en el texto. Por otra parte, el grupo de fenómenos agrupados, por economía de lenguaje, bajo la expresión "bloqueo institucional" es, para ser honestos, más diverso y complejo que lo que el lenguaje natural puede ofrecer con estas expresiones. El autor refiere varios fenómenos así agrupados: "anulación de poder de respuesta del Estado", "colapso en el cumplimiento de las tareas", "omisiones u obrar negligente", "situación de parálisis o estancamiento", etc., y aquí nuevamente los casos citados en algunas ocasiones no encajan en estas categorías o las desbordan. Así, por ejemplo, el proceso de desegregación de la sociedad norteamericana, al que apuntan varios de los fallos estructurales citados en la tesis, dista de poder ser explicado a partir de un mero "bloqueo institucional"; la dinamización de la política para atender el desplazamiento forzado en Colombia no se puede calificar con pretensiones de acierto bajo la idea de la "anulación de poder de respuesta del Estado", y una situación similar podría predicarse de los fallos que le dan impulso a la política ali- 
mentaria en India, la magnitud del problema y la ausencia de soluciones no obedecía a un bloqueo institucional en el propio sentido del término.

El segundo escenario es un cuestionamiento general al lugar que tiene la descripción de las prácticas remediales, o de reparaciones, de los tribunales internacionales de derechos humanos en el programa general de la tesis. Aquí el autor juega con las gramáticas de la semejanza, con lo que Wittgenstein llamaría los parecidos de familia, entre los fallos estructurales de los máximos tribunales internos y las sentencias de una corte internacional que advierte el incumplimiento de un tratado internacional. La sentencia del caso Campo Algodonero de la Corte Interamericana de Derechos Humanos tiene poco que ver con el caso Broniowski de la Corte Europea de Derechos Humanos, que a su vez tienen poco que ver con el caso Grootboom del máximo tribunal surafricano. No hay en aquellos casos un problema de legitimidad democrática; en estricto sentido, la naturaleza de las relaciones de poderes es otra, y el marco jurídico asaz diferente. Pero a la vez, es también posible advertir las similitudes, la escala de los remedios, la moción para que los órganos representativos retomen la agenda, el impacto perseguido sobre amplias capas de la población. El excurso de la tesis por la práctica de los tribunales internacionales de derechos humanos deja cabos sueltos que después no son bien atados en el resto del trabajo. No podían serlo. Porque los fundamentos de las reparaciones y la naturaleza de los problemas y el contexto son diferentes. Asimilarlos supone también el deber de ajustar el marco conceptual, y las baterías para el análisis.

El tercer escenario de mejora es un cuestionamiento sobre la representatividad de la muestra que sirve para desatar el análisis. En relación con la precisión de las categorías de la ontología propia del fenómeno hay un desfile importante de casos, en el que se alcanza a colar uno del máximo tribunal argentino, pero no hay en ninguna parte del texto una reflexión sobre la representatividad de la muestra. Este brío inicial de abordar una importante multiplicidad de casos se va reduciendo hasta que en el último capítulo, dedicado a dar cuenta del balance de los fallos estructurales después de los años, el autor se concentra en tres decisiones, de tres de los casos examinados: Estados Unidos, Sudáfrica y Colombia. Y en algún sentido metodológico esto está más que justificado. Sin embargo, lo que se gana en profundidad se pierde en extensión. El problema es que, por un lado, sea a partir de esta reducida evidencia que el autor pretenda soportar las conclusiones sobre la eficacia relativa de estos ejercicios, sobre sus limitaciones congénitas ahora reveladas y sobre el exceso de confianza de los entusiastas de esta práctica; y que, por el otro, sea en ella que se busque soportar las conclusiones sobre la importancia de los efectos simbólicos, el carácter inestimable de la acción social y de lucha política, y las razones para no desechar los fallos estructurales como parte del repertorio de las agendas transformadoras. 
En todo caso, y esto debe ser remarcado como colofón, estos tres defectos no alcanzan a desmontar la solidez de una investigación adelantada con tino y con suficiencia. No alteran la validez de unas conclusiones logradas con el ejercicio y el arte de la pluma mejor. No pueden empañar un trabajo de investigación que absorbe al lector desde las primeras páginas, que lo acompaña por intrincados vericuetos llenos de estimulantes referencias, que no deja de espolear el espíritu de la crítica y que vuelve siempre a reafirmar los valores más altos de la tradición constitucional. 